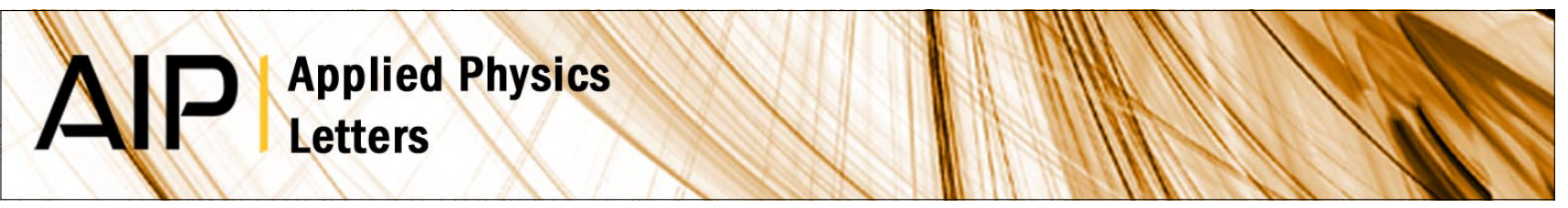

\title{
Energetic stability, structural transition, and thermodynamic properties of $\mathrm{ZnSnO3}$
}

Huiyang Gou, Jingwu Zhang, Zhiping Li, Gongkai Wang, Faming Gao et al.

Citation: Appl. Phys. Lett. 98, 091914 (2011); doi: 10.1063/1.3562013

View online: http://dx.doi.org/10.1063/1.3562013

View Table of Contents: http://apl.aip.org/resource/1/APPLAB/v98/i9

Published by the AIP Publishing LLC.

\section{Additional information on Appl. Phys. Lett.}

Journal Homepage: http://apl.aip.org/

Journal Information: http://apl.aip.org/about/about_the_journal

Top downloads: http://apl.aip.org/features/most_downloaded

Information for Authors: http://apl.aip.org/authors

\section{ADVERTISEMENT}
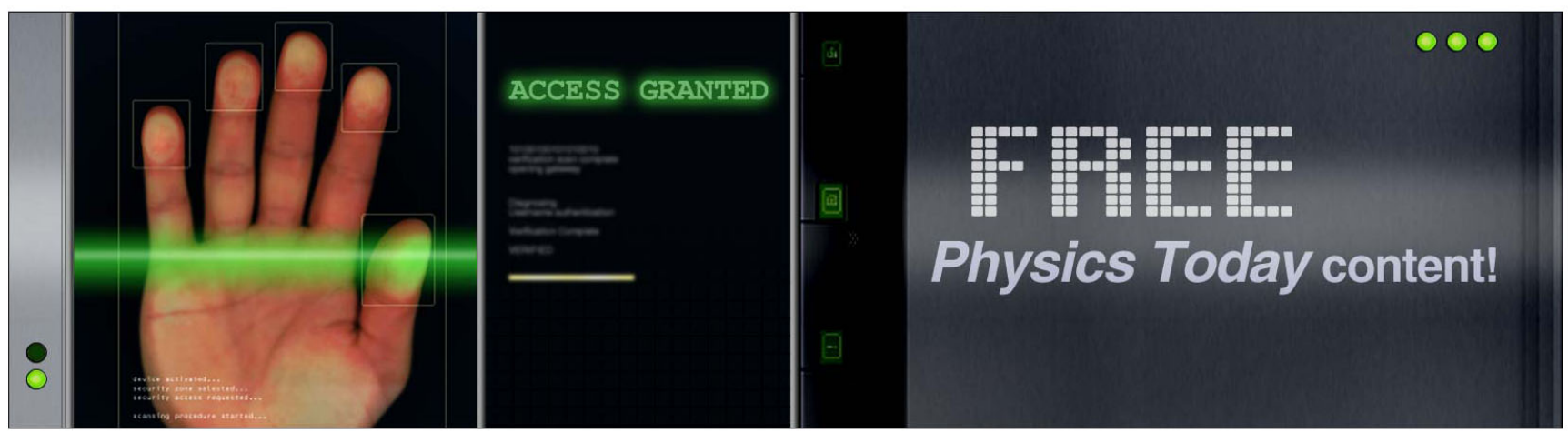


\title{
Energetic stability, structural transition, and thermodynamic properties of $\mathrm{ZnSnO}_{3}$
}

\author{
Huiyang Gou, ${ }^{1,2}$ Jingwu Zhang, ${ }^{2}$ Zhiping Li, ${ }^{3}$ Gongkai Wang, ${ }^{1}$ Faming Gao, ${ }^{3}$ \\ Rodney C. Ewing, ${ }^{4}$ and Jie Lian ${ }^{1, a)}$ \\ ${ }^{1}$ Department of Mechanical, Aerospace, and Nuclear Engineering, Rensselaer Polytechnic Institute, Troy, \\ New York 12180, USA \\ ${ }^{2}$ State Key Laboratory of Metastable Materials Science and Technology and College of Material Science \\ and Engineering, Yanshan University, Qinhuangdao 066004, People's Republic of China \\ ${ }^{3}$ Key Laboratory of Applied Chemistry, Yanshan University, Qinghuangdao 066004, \\ People's Republic of China \\ ${ }^{4}$ Departments of Geological Sciences and Materials Science \& Engineering, University of Michigan, \\ Ann Arbor, Michigan 48109-005, USA
}

(Received 20 June 2010; accepted 11 February 2011; published online 4 March 2011)

\begin{abstract}
First principles calculations were performed on $\mathrm{ZnSnO}_{3}$ polymorphs to understand their energetic stability and structural transition under high pressure environments. The experimentally-identified ilmenite (IL)-type and $\mathrm{LiNbO}_{3}(\mathrm{LN})$-type $\mathrm{ZnSnO}_{3}$ may coexist at zero pressure considering the effect of zero point energy. IL-type $\mathrm{ZnSnO}_{3}$ becomes unstable under high pressure due to the appearance of imaginary frequency in phonon spectra. Enthalpy differences suggest that the phase stability follows the sequence: $\mathrm{ZnO}+\mathrm{SnO}_{2}$ below $5.9 \mathrm{GPa}, \mathrm{Zn}_{2} \mathrm{SnO}_{4}+\mathrm{SnO}_{2}$ up to $7.1 \mathrm{GPa}$, and LN-type phase above 7.1 GPa. Pressurization at $34.5 \mathrm{GPa}$ causes a phase transformation from the LN-type to the orthorhombic $\mathrm{CdSnO}_{3}$-type. Thermodynamic properties including Helmholtz free energy, specific heat at constant volume and Debye temperature were also calculated. (C) 2011 American Institute of Physics. [doi:10.1063/1.3562013]
\end{abstract}

Perovskite-type oxides $\left(\mathrm{ABO}_{3}\right)$ have attracted considerable attentions due to their potential applications as the ferroelectric, piezoelectric, pyroelectric, and nonlinear optical materials. ${ }^{1-7}$ Zinc stannate, $\mathrm{ZnSnO}_{3}$, with polar $\mathrm{LiNbO}_{3}(\mathrm{LN})$-type structure (space group of $R 3 c$ ) has recently been synthesized upon high pressurization above $7 \mathrm{GPa}$ with an estimated polarization of $59 \mu \mathrm{C} / \mathrm{cm}^{2}{ }^{8}$ Meanwhile, the heteroepitaxial $\mathrm{Zn}$-based oxide thin film was also fabricated with a high ferroelectric polarization of $47 \mu \mathrm{C} / \mathrm{cm}^{2}{ }^{9}$. It is, thus, expected that $\mathrm{ZnSnO}_{3}$ would be an excellent candidate for lead-free ferroelectric materials. ${ }^{5-7}$

For $\mathrm{ZnSnO}_{3}$, various structures have been found in the experiments. In addition to LN-type structure, ${ }^{8}$ ilmenite (IL)type $\mathrm{ZnSnO}_{3}$ was synthesized by an ion exchange method, ${ }^{10}$ and nanostructured hexagonal and cubic perovskite-type structures were also observed. ${ }^{11-16}$ Theoretical calculations based on density functional theory (DFT) were performed to understand their structural, electronic and optical properties. ${ }^{17,18}$ Spontaneous polarization, dynamical and nonlinear optical properties were theoretically investigated to understand origins of physical properties of $\mathrm{ZnSnO}_{3} .{ }^{19} \mathrm{~A}$ recent DFT study on the structural and electronic properties of $\mathrm{ZnSnO}_{3}$ compositions reported a phase transformation from $\mathrm{Zn}_{2} \mathrm{SnO}_{4}-1 / 2 \mathrm{SnO}_{2}$ mixed phases to LN-type $\mathrm{ZnSnO}_{3}$ under a low pressure of $2 \mathrm{GPa},{ }^{20}$ below the critical transition pressure observed experimentally $(\sim 7 \mathrm{GPa}){ }^{8}{ }^{8}$ Despite that both IL and LN structure types were synthesized previously under ambient conditions, recent high pressure experiments only reported the synthesis of LN-type with no evidence of the formation of IL-type phase. ${ }^{21}$ The fundamental understanding of structural properties of $\mathrm{ZnSnO}_{3}$ will be critical for

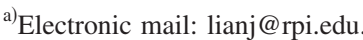

designing and developing ferroelectric oxides. The phase transformation process among different polymorphs under high pressure conditions is not fully understood yet. ${ }^{8-15}$ In addition, limited thermodynamic properties are available due to the difficulty of synthesizing high quality samples for measurements.

In this letter, first principles techniques were employed to investigate the relative phase stability of $\mathrm{ZnSnO}_{3}$ polymorphs under high pressure environments to understand the stability of crystal structure and their physical and thermodynamic properties. Our calculations indicate that IL-type and $\mathrm{LN}$-type $\mathrm{ZnSnO}_{3}$ may coexist at zero pressure considering the effect of zero point energy (ZPE). IL-type $\mathrm{ZnSnO}_{3}$ becomes unstable under high pressure based on the calculations of phonon spectra. In contrast, LN-type phase is favorable above $7.1 \mathrm{GPa}$, in excellent agreement with experimentally determined critical pressure for synthesizing stable LNtype phase by solid synthesis route. Furthermore, a phase transition occurs at $34.5 \mathrm{GPa}$ from LN-type structure to a orthorhombic $\mathrm{CdSnO}_{3}$-type structure. These results provide theoretical insights in understanding the phase stability, which forms a scientific basis for designing materials by high pressure.

Calculations of $\mathrm{ZnSnO}_{3}$ phases were performed with CASTEP code ${ }^{22}$ based on DFT. The exchange and correlation functional was treated by generalized gradient approximation-Perdew-Burke-Ernzerhof. ${ }^{23}$ The cutoff energy of $380 \mathrm{eV}$ and $k$-points of $6 \times 6 \times 6$ for all hypothetical structures were applied to calculate the total energy and enthalpy. The phonon dispersion and phonon density of states (PDOS) of IL-type and $\mathrm{LN}$-type $\mathrm{ZnSnO}_{3}$ was obtained with a cutoff energy of $660 \mathrm{eV}$ using the linear response method. ${ }^{24}$ The cubic $(c-)$ and hexagonal $(h-) \mathrm{ZnO}$, tetragonal rutile $\mathrm{SnO}_{2}$, 
TABLE I. Calculated lattice parameters, $a(\AA), b(\AA)$, and $c(\AA)$, difference in total energy, $\Delta E$ (eV/f.u.), and heat of formation $\Delta H$ (eV/f.u.) of $\mathrm{ZnSnO}_{3}$ with all the hypothetical structures and compared with experimental data.

\begin{tabular}{ccccc}
\hline \hline Phases & Space group & Lattice parameters & $\Delta E$ & $\Delta H_{f}$ \\
\hline $\mathrm{ZnSnO}_{3}$ & $R 3 c$ & $a=5.387(5.262),{ }^{\mathrm{a}} c=14.344(14.003){ }^{\mathrm{a}}$ & 0 & 0.15 \\
& $R-3$ & $a=5.419(5.284),{ }^{\mathrm{b}} c=14.348(14.091)^{\mathrm{b}}$ & 0.09 & 0.23 \\
& $P m-3 m$ & $a=4.086$ & 3.76 & 3.90 \\
& $R-3 c$ & $a=5.429, c=14.387$ & 0.11 & 0.25 \\
& Pnma & $a=5.422, b=7.994, c=5.428$ & 0.22 & 0.36 \\
& $C m c m$ & $a=3.082, b=9.934, c=7.653$ & 0.85 & 1.00 \\
\hline \hline
\end{tabular}

${ }^{\mathrm{a}}$ Reference 8 .

${ }^{\mathrm{b}}$ Reference 10.

and cubic spinel $\mathrm{Zn}_{2} \mathrm{SnO}_{4}$ were adopted for enthalpy calculations.

Six possible structures for $\mathrm{ZnSnO}_{3}$ were considered including cubic perovskite (space group: $P m-3 m),{ }^{14}$ IL-type (space group: $R-3$ ),${ }^{10}$ LN-type (space group: $R 3 c$ ) structures, ${ }^{8} \quad \mathrm{CdSnO}_{3}$-type (space group: Pnma), ${ }^{25}$ $\mathrm{HgSnO}_{3}$-type (space group: $R-3 c$ ), ${ }^{26}$ and post perovskite $(p p v)$-type (space group: $\mathrm{Cmcm}$ ) structure. ${ }^{27}$ For each structure, the lattice parameters and atomic positions were fully optimized. The calculated lattice parameters shown in Table I are in good agreements with experimental results. ${ }^{8,10}$ The calculated total energies versus volume ( $E$ - $V$ curve) of the possible structures are shown in Fig. 1(a). Among all possible structures, LN-type structure has the lowest total energy at $T=0 \mathrm{~K}$; whereas total energy of the cubic perovskite structure is much larger than that of LN-type structure, and the difference can be as large as $3.76 \mathrm{eV} / \mathrm{f}$.u. The larger energy difference suggests that the cubic perovskite phase of $\mathrm{ZnSnO}_{3}$ is difficult to form under ambient conditions. Also, the total energy of the $\mathrm{CdSnO}_{3}$-type phase intersects with that of both IL-type and LN-type phases, suggesting that structural modifications may occur under extreme environments. For experimentally synthesized IL-type and LN-type phases, no phase transition can be observed under studied compression regimes from $E-V$ curves despite that both volumes (difference by $1.4 \%$ ) (Ref. 8) and calculated total energy (difference by $0.085 \mathrm{eV}$ ) are similar for IL-type phase and LN-type phase. ${ }^{10,18}$ Whereas based on the study of Ko and Prewitt, ${ }^{28}$ IL-type phase may transform to LN-type phase due to the reordering of cations under high pressurization for $\mathrm{MnTiO}_{3}$ and possible $\mathrm{FeTiO}_{3}, \mathrm{ZnGeO}_{3}$, and $\mathrm{MgGeO}_{3}$ phases.

We, thus calculated the difference in total energy of $\mathrm{Zn} B \mathrm{O}_{3}(B=\mathrm{Si}, \mathrm{Ge}, \mathrm{Sn}$, and $\mathrm{Pb})$ in both IL-type and LN-type

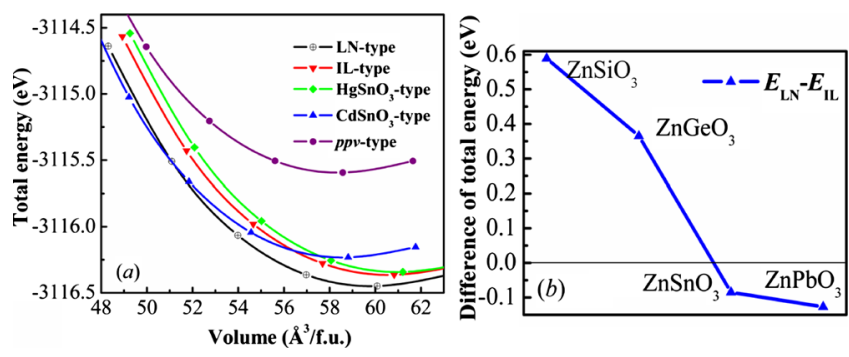

FIG. 1. (Color online) Calculated total energy as a function of volume ( $E$ - $V$ curve) for six possible structures for $\mathrm{ZnSnO}_{3}$ (a) and total energy difference of $\mathrm{ZnBO}_{3}(B=\mathrm{Si}, \mathrm{Ge}, \mathrm{Sn}$, and $\mathrm{Pb})$ between IL-type and LN-type structures (b)
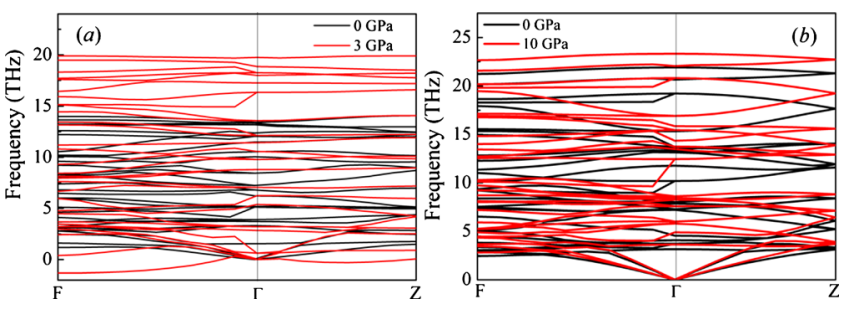

FIG. 2. (Color online) Calculated phonon spectra of IL-type (a) and LNtype (b) phases under both zero and high pressure.

structures as shown in Fig. 1(b). The difference in total energy decreases monotonically from $\mathrm{Si}$ phase $(0.60 \mathrm{eV}), \mathrm{Ge}$ phase $(0.37 \mathrm{eV})$ to $\mathrm{Sn}(0.09 \mathrm{eV})$ phase, suggesting that ILtype phase is energetically favorable as compared with LNtype phase; while for $\mathrm{Pb}$-contained phase, $\mathrm{LN}$-type phase is more favorable than IL-type phase. The total energy difference between IL-type and LN-type $\mathrm{ZnSnO}_{3}$ is small within the range in which ZPE correction may become important for their relative structural stability. ${ }^{29}$ The ZPE derived from the PDOS (Refs. 30 and 31) are $0.23 \mathrm{eV} / \mathrm{unit}$ and $0.31 \mathrm{eV} /$ unit for IL-type and LN-type structures, respectively. Considered the effect of ZPE, the total energy difference between IL-type and LN-type is only $\sim 0.005 \mathrm{eV} /$ unit, which suggests that these two phases may coexist under ambient conditions. Moreover, the phonon spectra of IL-type and LNtype phases in both zero and high pressures (up to $10 \mathrm{GPa}$ ) were calculated to understand the structural stability of $\mathrm{ZnSnO}_{3}$ polymorphs as displayed in Figs. 2(a) and 2(b). It can be seen that at zero pressure, all phonon branches of both phases have real frequency, indicating that these two phases are thermodynamically stable. However, at enhanced pressures (e.g., $1.5 \mathrm{GPa}, 3 \mathrm{GPa}, 5 \mathrm{GPa}$ up to $10 \mathrm{GPa}$ ), IL-type phase becomes unstable, as evidenced by the appearance of imaginary frequency in the $\Gamma-F$ direction, explaining why IL-type phase cannot be easily obtained in the high pressure experiment. $^{21}$

To further understand the effect of the possible synthesis routes in experiments, we also calculated the formation enthalpy $\left\{\Delta H=E_{\text {total }}\left(\mathrm{ZnSnO}_{3}\right)-\left[E_{\text {total }}(\mathrm{ZnO})+E_{\text {total }}\left(\mathrm{SnO}_{2}\right)\right]\right\}$. All of the proposed phases of $\mathrm{ZnSnO}_{3}$ have positive formation enthalpies (see Table I), suggesting that these polymorphs are not energetically favorable and cannot be synthesized by solid synthesis routes $\left(\mathrm{ZnO}+\mathrm{SnO}_{2}=\mathrm{ZnSnO}_{3}\right)$ at ambient conditions. These polymorphs can be stabilized under extreme conditions, such as high pressure or high temperature, as demonstrated by experimental observations. ${ }^{8}$ In view of the structural transition of $\mathrm{ZnSnO}_{3}$, we also calculated the enthalpy difference of mixed constituent oxides $(\mathrm{ZnO}$ $\left.+\mathrm{SnO}_{2},\left(\mathrm{Zn}_{2} \mathrm{SnO}_{4}+\mathrm{SnO}_{2}\right) / 2\right)$, IL-type and LN-type phases [Fig. 3(a)]. The mixed constituent oxides $\left(h-\mathrm{ZnO}+\mathrm{SnO}_{2}\right)$ are preferable relative to the other possible phases below 5.9 GPa. From 5.9 to $7.1 \mathrm{GPa}$, the mixed constituent oxides of $\mathrm{Zn}_{2} \mathrm{SnO}_{4}+\mathrm{SnO}_{2}$ become more favorable, in agreement with the experimental results at the mediated pressure condition. ${ }^{8}$ Above $7.1 \mathrm{GPa}$, the $\mathrm{LN}$-type $\mathrm{ZnSnO}_{3}$ phase is more stable than its constituents at least at low temperature, consistent with the experimental results, in which $\mathrm{LN}$-type $\mathrm{ZnSnO}_{3}$ can be obtained at $7 \mathrm{GPa}^{8}{ }^{8}$ To study the structural transition from LN-type to $\mathrm{CdSnO}_{3}$-type phases, the enthalpy difference $\left(H x-H_{\mathrm{LN}}\right)$ at $T=0 \mathrm{~K}$ versus pressure $(P)[$ Fig. 3(b)] was calculated to determine transition pressure $\left(P_{\mathrm{t}}\right)$. We found that 


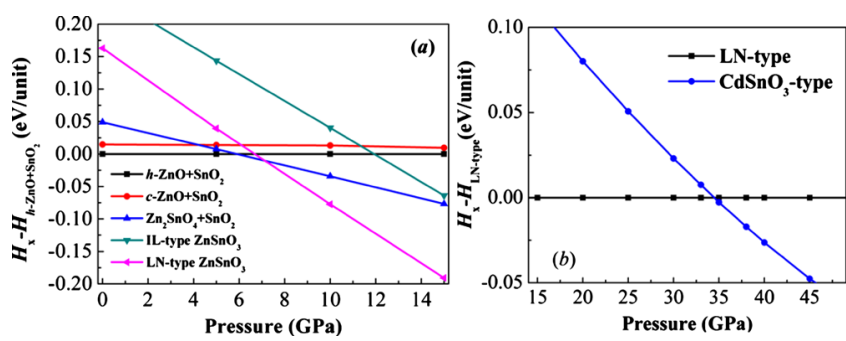

FIG. 3. (Color online) Calculated enthalpy differences, $H_{\mathrm{x}}-H_{h-\mathrm{ZnO}+\mathrm{SnO} 2}$, among mixed constituent oxides $\left[\mathrm{ZnO}+\mathrm{SnO}_{2},\left(\mathrm{Zn}_{2} \mathrm{SnO}_{4}+\mathrm{SnO}_{2}\right) / 2\right]$, ILtype, and $\mathrm{LN}$-type $\mathrm{ZnSnO}_{3}$ (a) and $H_{\mathrm{x}}-H_{\mathrm{LN} \text {-type }}$ between LN-type and $\mathrm{CdSnO}_{3}$-type phases (b) as a function of pressure $(P)$ at $T=0 \mathrm{~K}$.

the phase transition from LN-type structure to the orthorhombic $\mathrm{CdSnO}_{3}$-type structure occurs at $34.5 \mathrm{GPa}$. $P_{\mathrm{t}}$ of $\mathrm{ZnSnO}_{3}$ is significantly larger than that of $\mathrm{ZnGeO}_{3}(15.6$ $\mathrm{GPa})$ (Ref. 32) and $\mathrm{MgGeO}_{3}$ (17.9 GPa) (Ref. 33) as observed in the experiments.

The temperature dependence of thermodynamic properties, such as Helmholtz-free energy, $\Delta F$, specific heat at constant volume, $C_{\mathrm{V}}$, and even Debye temperature, $\Theta_{\mathrm{D}}$, for both IL-type and LN-type phases can be derived from PDOS, as shown in Fig. 4. The calculated $\Delta F$ indicates that IL-type phase is more energetically favorable as compared to $\mathrm{LN}$ type phase. ${ }^{18}$ The occurrence of IL-type phase in the experiment is thus highly dependent on the synthesis route. From Fig. 4, we found that at low temperature, $C_{\mathrm{V}}$ exhibits a sharp increase up to about $400 \mathrm{~K}$, and at high temperature, $C_{\mathrm{V}}$ is close to a constant, so-called Dulong-Petit limit. ${ }^{34} C_{\mathrm{V}}$ of LN-type phase is smaller than that of IL-type phase in the studied range of temperature. At $300 \mathrm{~K}, C_{\mathrm{V}}$ of IL-type $\mathrm{ZnSnO}_{3}(108.9 \mathrm{~J} / \mathrm{mol} \mathrm{K})$ is similar to that of $\mathrm{BaSnO}_{3}(103$ $\mathrm{J} / \mathrm{mol} \mathrm{K}){ }^{35}$ but much larger than these of $\mathrm{ZnSiO}_{3}(85.1 \mathrm{~J} / \mathrm{mol}$ $\mathrm{K}){ }^{36} \mathrm{MgSiO}_{3}$ [78.4 (Ref. 37) or 79.2 J/mol K (Ref. 38)], and $\mathrm{MgGeO}_{3}(87.3 \mathrm{~J} / \mathrm{mol} \mathrm{K}$ ) (Ref. 39) with the same structure. Debye temperature of IL-type phase [Fig. 4] is significantly smaller than that of the LN-type phase with increasing temperature. For LN-type $\mathrm{ZnSnO}_{3}, \Theta_{\mathrm{D}}$ is $662 \mathrm{~K}$ at $300 \mathrm{~K}$; whereas $\Theta_{\mathrm{D}}$ of $\mathrm{ZnSnO}_{3}(500 \mathrm{~K})$ is relatively smaller than that of $\mathrm{MgGeO}_{3}(777 \mathrm{~K})$ at $300 \mathrm{~K}$ (Ref. 39) with the same IL-type structure. There are currently no reports on thermodynamic parameters in both experiments and calculations for $\mathrm{ZnSnO}_{3}$. Therefore, our calculations may provide a predic-

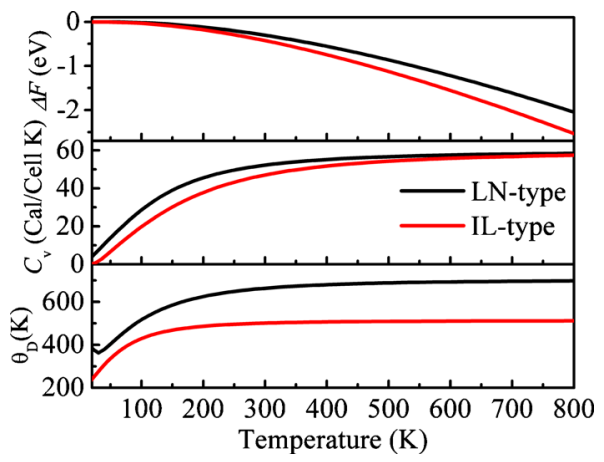

FIG. 4. (Color online) Calculated Helmholtz free energy, $\Delta F$, specific heat at constant volume, $C_{\mathrm{V}}$, and Debye temperature, $\Theta_{\mathrm{D}}$, as a function of temperature of both IL-type and LN-type $\mathrm{ZnSnO}_{3}$. tion and stimulate the continued studies in the either experiments or simulations.

This work was supported by the Materials Science of Actinides, an Energy Frontier Research Center funded by Office of Basic Energy Sciences under Award No. DESC0001089.

${ }^{1}$ D. Vanderbilt, Curr. Opin. Solid State Mater. Sci. 2, 701 (1997).

${ }^{2}$ R. E. Cohen, J. Phys. Chem. Solids 61, 139 (2000).

${ }^{3}$ R. Resta, Modell. Simul. Mater. Sci. Eng. 11, R69 (2003).

${ }^{4}$ K. M. Rabe and P. Ghosez, Physics of Ferroelectrics (Springer, Berlin, 2007), pp. 117-174.

${ }^{5}$ G. Sághi-Szabó, R. E. Cohen, and H. Krakauer, Phys. Rev. Lett. 80, 4321 (1998).

${ }^{6}$ J. B. Neaton, C. Ederer, U. V. Waghmare, N. A. Spaldin, and K. M. Rabe, Phys. Rev. B 71, 014113 (2005).

${ }^{7}$ G. Catalan and J. F. Scott, Adv. Mater. (Weinheim, Ger.) 21, 2463 (2009).

${ }^{8}$ Y. Inaguma, M. Yoshida, and T. Katsumata, J. Am. Chem. Soc. 130, 6704 (2008).

${ }^{9}$ J. Y. Son, G. Lee, M. H. Jo, H. Kim, H. M. Jang, and Y. H. Shin, J. Am. Chem. Soc. 131, 8386 (2009).

${ }^{10}$ D. Kovacheva and K. Petrov, Solid State Ion. 109, 327 (1998)

${ }^{11}$ I. Stambolova, K. Konstantinov, D. Kovacheva, P. Peshev, and T. Donchev, J. Solid State Chem. 128, 305 (1997).

${ }^{12}$ S. Y. Shen and T. S. Zhang, Sens. Actuators B 12, 5 (1993).

${ }^{13}$ M. Inagaki, T. Kuroishi, Y. Yamashita, and M. Urata, Z. Anorg. Allg. Chem. 527, 193 (1985)

${ }^{14}$ J. Xu, X. Jia, X. Lou, and J. Shen, Solid-State Electron. 50, 504 (2006).

${ }^{15}$ B. Y. Geng, C. H. Fang, F. M. Zhan, and N. Yu, Small 4, 1337 (2008).

${ }^{16}$ Z. Wang, J. Liu, F. Wang, S. Chen, H. Luo, and X. Yu, J. Phys. Chem. C 114, 13577 (2010).

${ }^{17}$ H. Wang, H. Huang, and B. Wang, Solid State Commun. 149, 1849 (2009).

${ }^{18}$ H. Y. Gou, F. M. Gao, and J. W. Zhang, Comput. Mater. Sci. 49, 552 (2010).

${ }^{19}$ J. Zhang, K. L. Yao, Z. L. Liu, G. Y. Gao, Z. Y. Sun, and S. W. Fan, Phys Chem. Chem. Phys. 12, 9197 (2010).

${ }^{20}$ M. Nakayama, M. Nogami, M. Yoshida, T. Katsumata, and Y. Inaguma, Adv. Mater. (Weinheim, Ger.) 22, 2579 (2010).

${ }^{21}$ C. A. Hoel, J. M. G. Amores, E. Moran, M. A. Alario-Franco, J. F. Gaillard, and K. R. Poeppelmeier, J. Am. Chem. Soc. 132, 16479 (2010).

${ }^{22}$ S. J. Clark, M. D. Segall, C. J. Pickard, P. J. Hasnip, M. J. Probert, K. Refson, and M. C. Payne, Z. Kristallogr. 220, 567 (2005).

${ }^{23}$ J. P. Perdew, K. Burke, and M. Ernzerhof, Phys. Rev. Lett. 77, 3865 (1996).

${ }^{24}$ K. Refson, S. J. Clark, and P. R. Tulip, Phys. Rev. B 73, 155114 (2006)

${ }^{25}$ H. Mizoguchi, H. W. Eng, and P. M. Woodward, Inorg. Chem. 43, 1667 (2004).

${ }^{26}$ M. Yoshida, T. Katsumata, and Y. Inaguma, Inorg. Chem. 47, 6296 (2008).

${ }^{27}$ Y. Inaguma, K. Hasumi, M. Yoshida, T. Ohba, and T. Katsumata, Inorg. Chem. 47, 1868 (2008).

${ }^{28}$ J. Ko and C. T. Prewitt, Phys. Chem. Miner. 15, 355 (1988).

${ }^{29}$ W. Zhong and D. Vanderbilt, Phys. Rev. B 53, 5047 (1996).

${ }^{30}$ X. Chen, W. Wolf, R. Podloucky, and P. Rogl, Phys. Rev. B 76, 092102 (2007).

${ }^{31}$ Y. Wang, J. A. Yan, and M. Y. Chou, Phys. Rev. B 77, 014101 (2008).

${ }^{32}$ H. Yusa, M. Akaogi, N. Sata, H. Kojitani, R. Yamamoto, and Y. Ohishi, Phys. Chem. Miner. 33, 217 (2006).

${ }^{33}$ K. Leinenweber, Y. Wang, T. Yagi, and H. Yusa, Am. Mineral. 79, 197 (1994)

${ }^{34}$ C. Kittel, Introduction to Solid State Physics, 7th ed. (Wiley, New York, 1996).

${ }^{35}$ T. Maekawa, K. Kurosaki, and S. Yamanaka, J. Alloys Compd. 416, 214 (2006).

${ }^{36}$ M. Akaogi, H. Yusa, E. Ito, T. Yagi, K. Suito, and J. T. Iiyama, Phys Chem. Miner. 17, 17 (1990).

${ }^{37}$ B. B. Karki and R. M. Wentzcovitch, J. Geophys. Res. 107, 2267 (2002).

${ }^{38}$ A. M. Hofmeister and E. Ito, Phys. Chem. Miner. 18, 423 (1992).

${ }^{39}$ T. Ashida, Y. Miyamoto, and S. Kume, Phys. Chem. Miner. 12, 129 (1985) 